\title{
Farming Related Trauma Injuries in Southern West Virginia With a Focus on Risks, Injury Trends, and Associated Co-morbidities
}

\author{
Ravi Viradia ${ }^{1}$, Frank H. Annie ${ }^{2}$, Maher Kali ${ }^{3,4}$, John D. Hayes ${ }^{5}$, Frederic Pollock ${ }^{5}$ \\ 1. Surgery, Charleston Area Medical Center/ West Virginia University, Charleston, USA 2. Cardiology, Charleston Area \\ Medical Center, Charleston, USA 3. Clinical Research, Charleston Area Medical Health Education and Research \\ Institute, Charleston, USA 4. Research, Charleston Area Medical Health Education and Research Institute, Charleston, \\ WV, USA 5. Surgery, Charleston Area Medical Center, Charleston, USA
}

Corresponding author: Frank H. Annie, frank.h.annie@camc.org

\section{Abstract \\ Background}

The implementation of safety policies in farming-related injuries in West Virginia has been lacking. Farming-related injuries have resulted in massive injuries that have resulted in life long injuries and death. Therefore, this study aims to review 12 years of our level 1 trauma data and describe the incidence rate and patterns of priority-related farming injuries in West Virginia, as well as the specific co-morbidities and related injuries that might be more susceptible to damage.

\section{Methods}

We examined 82 cases of farm-related injuries that required trauma-priority related intervention from 2005 2016. We harvested data from the Charleston Area Medical Center Trauma registry to investigate associated injuries. We defined farm equipment as any mechanical or automated tool used on a farm for related farm upkeep or farm-related activity. Multinomial logistic regression was used to understand the overall impact on the differing effects of years of injuries.

\section{Results}

The total number of farming-related injury cases was 82 . The most statistically suggestive finding was those that had a positive narcotics urine test at $(\mathrm{p}=0.062)(-.3230-12.82)$. Those with a history of CHF (congestive heart failure) also had a significant statistical relationship at $(\mathrm{p}=0.001)(-5.477-1.394)$. Alcohol use disorder was also a significant statistical relationship $(\mathrm{p}=0.012)(-5.127--.6728)$. The most common injuries were concussions at $18 \%$ ( $15 / 82)$ followed by rib fractures at $17 \%(14 / 82)$.

\section{Conclusion}

Received 04/22/2019

Review began 05/30/2019 Review ended 10/21/2019 Published 10/30/2019

๑) Copyright 2019

Viradia et al. This is an open access article distributed under the terms of the Creative Commons Attribution License CC-BY 3.0., which permits unrestricted use, distribution, and reproduction in any medium, provided the original author and source are credited.
Farming-related injuries appear to have increased risks on specific body and organ systems, as described in our initial data analysis. Specific co-morbidities also have been documented to show a higher risk of injury and would need further investigation. Specific years show a higher prevalence of farming injuries compared to other years. Further research is needed to explore these underlying findings.

\section{Categories: Trauma}

Keywords: farming, injuries

\section{Introduction}

The implementation of safety policies in farming-related injuries in West Virginia has been lacking. Farming-related injuries have resulted in massive injuries that have resulted in life long injuries and death. Therefore, this study aims to review 12 years of our level 1 trauma data and describe the incidence rate and patterns of priority-related farming injuries in West Virginia farmers, as well as the specific comorbidities and related injuries that might be more susceptible to damage [1]. Farming tools evolved over the years from planting by using bare hands to sculpture a stony cultivating tool [2-7]. The rapid growth of the world population and the increasing food demand lead to the use of fertilizers and chemicals to enhance faster corps production.

Moreover, farming came along with animal domestication for different purposes, from pulling a plow and transporting harvest, in addition to raising cattle and different kinds of farm animals for the meat and milk. Moreover, the farming culture involved every family member, young or old male or female in helping on the field. Thus, dealing with such a complex environment lead to different types of injuries from operating a machine or contact with an animal and even poisoning from chemical exposure, and affected all ages and genders [8-16]. The state of West Virginia has farming communities from small family-run farms to mid and 


\section{Cureus}

large scale industrial crops producing farms; however, the implementation of safety policies in farmingrelated injuries in West Virginia has been lacking. Farming-related injuries have resulted in massive injuries that have resulted in life long injuries and death. Therefore, this study aims to review 12 years of our level 1 trauma data and describe the incidence and patterns of priority-related farming injuries in our tertiary medical center in southern West Virginia, as well as the specific co-morbidities and related injuries of the body that might be more susceptible to damage.

\section{Materials And Methods}

We examined 82 cases of farm-related injuries that required trauma-priority related intervention from 2005 2016. We harvested data from the Charleston Area Medical Center Trauma registry to investigate associated injuries. We defined farm equipment as any mechanical or tool used on a farm for related farm upkeep or farm-related activity. Multinomial logistic regression was used to understand the overall impact on the differing effects of years of injuries.

\section{Results}

The variables collected are as follows: The sample size representing the total number of farming-related injury cases was 82 (Table 1). The average age was 60.8 years. The most common injuries were concussions at $18 \%-(15 / 82)$ followed by rib fractures at 17\%-(14/82). In regards to 2005-2018 injury, the highest was in 2012 at $14.63 \%$ while the lowest was in 2007 at $1.22 \%$ (figure 1 ). The most statistically suggestive finding had a positive narcotics urine test at $(\mathrm{p}=0.062)(-.3230-12.82)$. Those with a history of CHF also had a significant statistical relationship $(\mathrm{p}=0.001)(-5.477-1.394)$. Alcohol use disorder was also a significant statistical relationship $(\mathrm{p}=0.012)(-5.127--.6728)$. 


\section{Cureus}

\begin{tabular}{|c|c|}
\hline Injuries & $\mathbf{N}=82$ \\
\hline Other Injury & 5 \\
\hline Amputation At Above Knee & 2 \\
\hline $2^{\text {nd }}$-Degree Burns & 1 \\
\hline Metacarpal Fracture & 1 \\
\hline Cerebral Concussion & 15 \\
\hline Cerebral Hematoma & 7 \\
\hline Cervical & 2 \\
\hline Crush Hand & 1 \\
\hline Spine Fracture & 3 \\
\hline Distal Radius & 2 \\
\hline Distal Tibia & 0 \\
\hline Fracture & 5 \\
\hline Finger Amputation & 3 \\
\hline Ribs Fracture & 14 \\
\hline Lateral Fracture & 1 \\
\hline Lumber Injury & 3 \\
\hline Lung & 1 \\
\hline Face Injury & 1 \\
\hline Metatarsal Fracture & 2 \\
\hline Pelvic & 8 \\
\hline Skin & 3 \\
\hline Finger Fracture & 2 \\
\hline
\end{tabular}

TABLE 1: Injuries 


\section{Cureus}

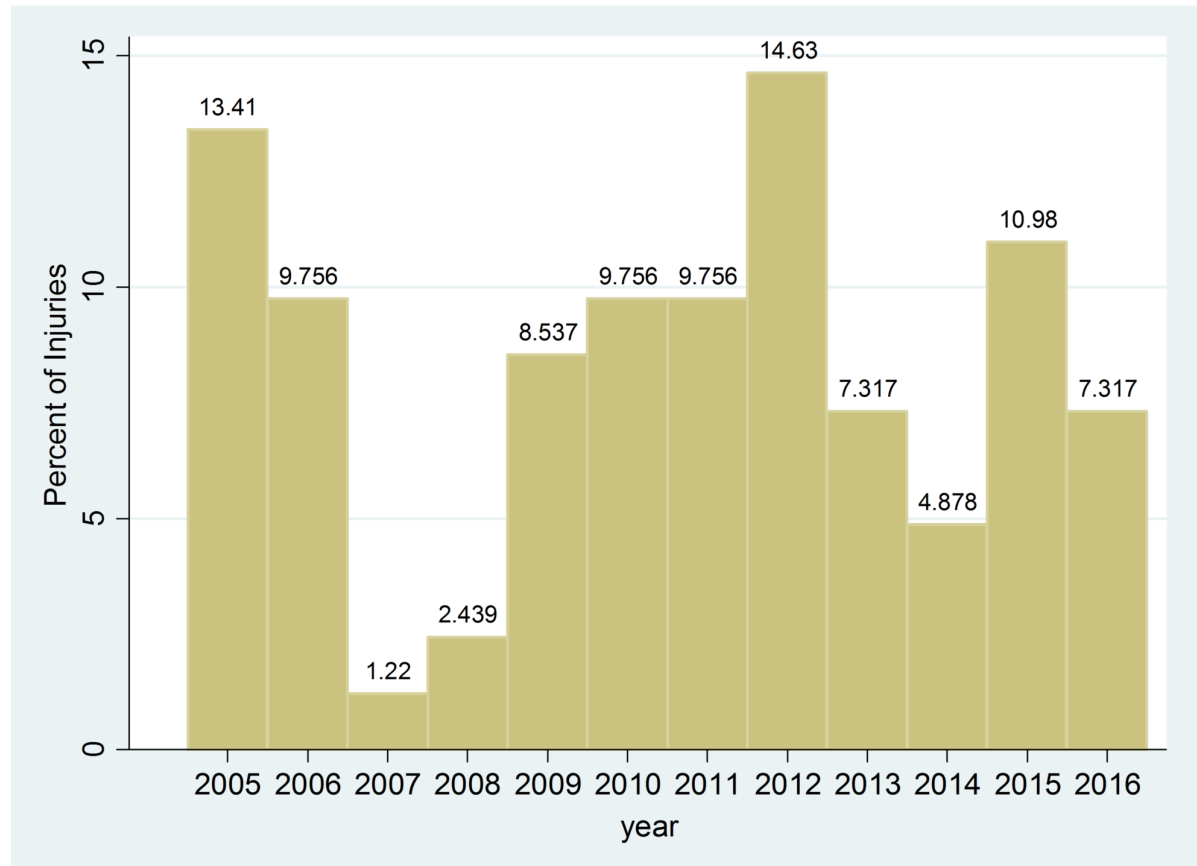

FIGURE 1: Injuries Through Time

\section{Discussion}

Farming related injuries in southern WV have been prevalent, and our retrospective data from our trauma registry has suggested that multiple organ systems are at risk of injury. Farming itself is a dangerous profession, and safety regulations in the occupation and the operating equipment involved are not as stringent as other specialties. Peek-Asa reported close to $10 \%$ of farmers get injured while working on the farm and 1769 death in Canada between 1990 and 2005, including children [1-7]. Our sample size consisted of farmers who were injured on a farm and were taken to our level 1 trauma center for further evaluation and work up. Again, we defined farm equipment as any mechanical or tool used on a farm for related farm upkeep or farm-related activity [3-5]. We found that the most common farming injury sustained was a concussion, followed by rib fractures and pelvic fractures. We also found that narcotic usage, congestive heart failure, and positive alcohol were statistically significant for an increase in injury. We also took our evaluation of data a step further to track the injury trends of the incidence during each year from 20052016. Our analysis found that 2012 to be the highest year with farming injuries presenting to our level 1 trauma center.

\section{Conclusions}

Farming-related injuries appear to have increased risks on specific body and organ systems, as described in our initial data analysis. Specific co-morbidities also have been established that show a higher risk of injury and would need further investigation. Specific years show a higher prevalence of farming injuries compared to other years. New research is required to explore these underlying findings. Farming-related injuries appear to have increased risks on specific body and organ systems, as described in our initial data analysis. Additionally, understanding the type of injuries will help the clinician to be better prepared to manage such injuries in rural medical centers. This study promotes awareness of the need for developing better public health occupational policies and preventive teaching programs to reduce these preventable injuries.

\section{Additional Information}

\section{Disclosures}

Human subjects: Consent was obtained by all participants in this study. CAMC Institute issued approval 17330. Animal subjects: All authors have confirmed that this study did not involve animal subjects or tissue. Conflicts of interest: In compliance with the ICMJE uniform disclosure form, all authors declare the following: Payment/services info: All authors have declared that no financial support was received from any organization for the submitted work. Financial relationships: All authors have declared that they have no financial relationships at present or within the previous three years with any organizations that might have an interest in the submitted work. Other relationships: All authors have declared that there are no other relationships or activities that could appear to have influenced the submitted work. 


\section{References}

1. Peek-Asa C, Zwerling C, Stallones L: Acute traumatic injuries in rural populations. Am J Public Health. 2004, 94:1689-1693. 10.2105/AJPH.94.10.1689

2. Ozegovic D,Voaklander DC: What we are not talking about: An evaluation of prevention messaging in print media reporting on agricultural injuries and fatalities. Am J Ind Med. 2011, 54:603-608. 10.1002/ajim.20967

3. Haan JM,Hauschild D,Patterson C, et al.: Fatal agricultural accidents in Kansas: A thirty-one-year study . Am Surg. 2018, 84:581-586.

4. Pickett W,King N,Lawson J, et al.: Farmers, mechanized work, and links to obesity . Prev Med. 2015, 70:5963. 10.1016/j.ypmed.2014.11.012

5. Walker-Bone K,Palmer KT : Musculoskeletal disorders in farmers and farm workers . Occup Med (Lond). 2002 , 52(8):441-50. 10.1093/occmed/52.8.441

6. Kruger MJ,Nell TA: The prevalence of the metabolic syndrome in a farm worker community in the Boland district, South Africa. BMC Public Health. 2017, 17:61. 10.1186/s12889-016-3973-1

7. Mentoor I,Kruger M,Nell T : Metabolic syndrome and body shape predict differences in health parameters in farm working women. BMC Public Health. 2018, 18:453. 10.1186/s12889-018-5378-9

8. Etherton JR,Myers JR,Jensen RC, et al.: Agricultural machine-related deaths. Am J Public Health. 1991, 81:766-768.

9. Voaklander DC,Hartling L,Pickett W, et al.: Work-related mortality among older farmers in Canada . Can Fam Physician. 1999, 45:2903.

10. Gerberich SG,Gibson RW,French LR, et al.: Machinery-related injuries:: Regional Rural Injury Study-I (RRIS -I). Accident Analysis \& Prevention. 1998, 30:793-804. 10.1016/S0001-4575(98)00032-3

11. Myers, J. R., Layne, L. A., \& Marsh, S. M: Injuries and fatalities to US farmers and farm workers 55 years and older. Am J Ind Med. 2008, 52:185-194. 10.1002/ajim.20661

12. Gunderson P,Gerberich S,Gibson R, et al.: Injury surveillance in agriculture . Am J Ind Med. 1990, 18:169178. 10.1002/ajim.4700180209

13. Browning SR,Truszczynska H,Reed D, et al.: Agricultural injuries among older Kentucky farmers: The farm family health and hazard surveillance study. Am J Ind Med. 2016, 33:341-353. 10.1002/(SICI)10970274(199804)33:4<341::AID-AJIM4>3.0.CO;2-X

14. Hartling L,Pickett W,Guernsey JR, et al.: Injuries associated with the farm harvest in Canada . Can Med Assoc J. 1998, 158:1493.

15. Rorat M,Thannhauser A,Jurek $\mathrm{T}$ : Analysis of injuries and causes of death in fatal farm-related incidents in Lower Silesia, Poland.. Ann Agric Environ Med. 2015, 22:271-274. 10.5604/12321966.1152079

16. Kumar, A., Varghese, M., \& Mohan, D: Equipment-related injuries in agriculture: An international perspective. Int J Inj Contr Saf Promot. 2000, 7:175-186. 10.1076/1566-0974(200009)7:3;1-N;FT175 